\title{
Great expectations: Different high-risk activities satisfy different motives
}

Barlow, M.D.; Woodman, Tim; Hardy, L.J.

\section{Journal of Personality and Social Psychology}

DOI:

$10.1037 / \mathrm{a} 0033542$

Published: 01/09/2013

Peer reviewed version

Cyswllt i'r cyhoeddiad / Link to publication

Dyfyniad o'r fersiwn a gyhoeddwyd / Citation for published version (APA):

Barlow, M. D., Woodman, T., \& Hardy, L. J. (2013). Great expectations: Different high-risk activities satisfy different motives. Journal of Personality and Social Psychology, 105(3), 458475. https://doi.org/10.1037/a0033542

Hawliau Cyffredinol / General rights

Copyright and moral rights for the publications made accessible in the public portal are retained by the authors and/or other copyright owners and it is a condition of accessing publications that users recognise and abide by the legal requirements associated with these rights.

- Users may download and print one copy of any publication from the public portal for the purpose of private study or research.

- You may not further distribute the material or use it for any profit-making activity or commercial gain

- You may freely distribute the URL identifying the publication in the public portal ?

Take down policy

If you believe that this document breaches copyright please contact us providing details, and we will remove access to the work immediately and investigate your claim. 
Running Head: MOTIVES FOR HIGH-RISK ACTIVITIES

Article accepted in its current form in Journal of Personality \& Social Psychology:

Barlow, M., Woodman, T., \& Hardy, L. (2013). Great expectations: Different high-risk activities satisfy different motives. Journal of Personality \& Social Psychology, 105, 458-475. doi:10.1037/a0033542.

Great Expectations: Different High-Risk Activities Satisfy Different Motives

Matt Barlow, Tim Woodman, and Lew Hardy

Bangor University, UK

Correspondence concerning this article should be addressed to: Tim Woodman, Institute for the Psychology of Elite Performance, Bangor University, Bangor, Gwynedd LL57 2DG, UK. Telephone: +44 1248388 256. Fax: +44 1248371 053. Email: t.woodman@bangor.ac.uk

Author Note:

The authors wish to thank two anonymous reviewers and Laura King for their critical and insightful comments on earlier drafts of this paper. 


\begin{abstract}
Research on people's motives for engaging in high-risk activities has typically been viewed through the single-focused lens of sensation seeking. We provide evidence that comprehensively challenges that view. First, we develop and confirm the structure of a threefactor measure of motives: the Sensation seeking, Emotion regulation and Agency Scale (SEAS; Study 1). We then use the SEAS to provide evidence of differential motives for two high-risk activities: skydiving and mountaineering. The motive for skydiving is strongly associated with sensation seeking; the motive for mountaineering is strongly associated with emotion regulation and agency, but not with sensation seeking (Study 2). We also show that these conclusions cannot be drawn from existing measures of personality and sensation seeking (Study 3). Finally, individuals who are motivated by emotion regulation and agency needs also have greater expectations regarding their emotion regulation and agency. It is these greater expectations that most successfully discriminate mountaineers from skydivers and control participants (Study 4). It is concluded that researchers should no longer consider risk-takers as a homogenous sensation seeking group and should consider risk-taking as a potential model of human endeavor. The SEAS can be used as a measure of motives for behavior whenever sensation seeking, agency, or emotion regulation is thought to be at the core of such motives, and the results are discussed in the context of encouraging personality researchers to consider the specific spontaneous behaviors that motivate different people.

Keywords: agency, emotion regulation, sensation seeking, risk-taking sport, mountaineering, skydiving
\end{abstract}




\section{Great Expectations: Different High-Risk Activities Satisfy Different Motives}

Many years ago the great British explorer George Mallory, who was to die on Mount Everest, was asked [by a New York Times journalist] why did he want to climb it. He said, 'Because it is there.' Well, space is there, and we're going to climb it, and the moon and the planets are there, and new hopes for knowledge and peace are there

$$
\text { - J.F. Kennedy's moon speech (1962) }
$$

Humans have evolved through taking risks. In fact, most human actions can be conceptualized as containing an element of risk: as we take our first step, we risk falling down; as we try a new food, we risk being disgusted; as we ride a bicycle, we risk falling over; as we go on a date, we risk being rejected; and as we travel to the moon, we risk not coming back. Humans and risk are intertwined and it is thus perhaps unsurprising that, despite the risk-averse society that appears to have recently evolved, many people crave danger, excitement and risk. This is exemplified in the current boom of high-risk activities such as skydiving and bungee jumping. The long-standing view is that participants of highrisk activities form a single homogenous group: sensation seekers (Zuckerman, 1979, 2007). And yet there are some risk-takers that appear to be motivated by something more. For example, in the early 1920's George Mallory's dogged pursuit of the summit of Mount Everest, which led to his death in $1924^{1}$, can hardly be considered "sensation seeking." Although Mallory's purported retort of "because it's there" is a lesson in prosaicness, it does little to shed light on understanding why people might voluntarily risk their own and others' life to achieve what appears to be a trivial and dangerous pursuit: to attempt to get to the top of a mountain only to come straight back down; or go to the moon only to come back.

Certainly, despite the long-standing view that all high-risk activities are motivated by

\footnotetext{
${ }^{1}$ Mount Everest was eventually climbed successfully for the first time in 1953.
} 
sensation seeking (Zuckerman, 1979, 2007), Mallory's and others' endeavors seem motivated by something very different and there appears to be an important lesson to learn from those who voluntarily choose to take risks for the achievement of a grand objective. In this paper, we explore the motives for such purposeful high-risk endeavors and use mountaineering as a model of such behavior. We aim to demonstrate that high-risk activities are not simply derived by sensation seeking but rather by something rather more intrapsychic, which we aim to unearth here. Although we use mountaineering as the investigative framework for this research the application is clearly considerably broader - as illustrated by Kennedy above and might be applied as a model of human endeavor.

\section{Sensation seeking}

Zuckerman (1994) suggested that sensation seekers display a willingness to take risks in order to experience the sensation rewards of "sensation-seeking activities" (p. 37) such as drug use, dangerous driving, and risky sports. For example, skydivers - especially novice and intermediate skydivers - frequently proclaim themselves "adrenaline junkies" (Celsi, Rose, \& Leigh, 1993, p. 16).

Conversely, mountaineering and other high-risk endeavors (e.g., polar expeditions) are largely devoid of sensation provision. Despite these clear differences, psychologists have typically satisfied themselves with explanations revolving around this sensation seeking model for all high-risk sports (e.g., Zuckerman, 1979, 1994, 2007). Acceptance of such a view has hampered research into the potential lessons that one might learn from individuals who voluntarily pursue great achievements in the face of danger. For example, polar expeditions (Leon, McNally, \& Ben-Porath, 1989), ocean sailing (Norris \& Weinman, 1996), ocean rowing (Woodman, Hardy, Barlow, \& Le Scanff, 2010), and mountaineering (Lester, $1983,2004)$ seem to reflect an experience that is antonymous to sensation seeking. Individuals engaged in these activities undergo hardship, suffering, and monotony on a daily 
basis (Loewenstein, 2007). Mountaineering, for example, not only requires extensive planning and preparation but the expedition itself - typically over many weeks - is often reported as toilsome and tedious (e.g., Ewert, 1994), and any pleasure is largely derived retrospectively. Most worthwhile human endeavors share many of the characteristics of mountaineering. That is, the vast majority of time on worthwhile projects is spent dealing with hardship, monotony, and setbacks. Furthermore, "thrills" are actively avoided in such endeavors. In mountaineering, thrills are typically associated with a loss of control (e.g., an avalanche, a fall) and an increased risk of serious injury or death (Kirkpatrick, 2011).

Sensation seeking is clearly a fruitless theoretical standpoint from which to understand the motives for such experiences. One alternative theoretical framework that appears particularly promising for examining motives for engagement in high-risk activities centers on the constructs of emotion regulation and agency.

\section{Emotion Regulation and Agency}

Emotion regulation is the term used to characterize the diverse processes involved in initiating, maintaining, and modulating the intensity, type, or duration of emotions (Gross \& Thompson, 2007; Thompson, 1994). It refers to actions that influence "which emotions we have, when we have them, and how we experience and express them" (Gross, 2002, p. 282). To be an agent is to influence intentionally one's functioning and life circumstances (Bandura, 2001, 2006). An agentic self presumes active and causal contributions to behavior and development (Bandura, 2001); the self is the author of internal states such as intent, belief, and desire (Little, Snyder, \& Wehmeyer, 2006). The most central and pervasive mechanism of agency is individuals' beliefs regarding their capabilities to exercise control over events that affect their lives (Bandura, 1997).

Participants of prolonged engagement high-risk activities (e.g., mountaineers, polar explorers) display a difficulty with emotion regulation and a diminished sense of agency in 
important aspects of everyday life (Hunt \& Daines, 2004; Leon et al., 1989; Woodman et al., 2010). Specifically, empirical and biographical evidence suggests that mountaineers display: below-average toleration of others' emotional needs (Hunt \& Daines, 2004); avoidance of emotional sharing (Roberts, 1986); a lack of interest in social interaction with a low perceived need for intimacy or affection (Lester, 1983); and a difficulty describing feelings (Woodman et al., 2010). These individuals also sense that the course of their life and the emotions engendered therein are dictated and driven by forces outside of their control (Lester, 1983, 2004).

Since a perceived difficulty to influence intentionally one's environment, behavior, and self-regulation, is widely acknowledged as antithetical to psychological well-being (deCharms, 1968; Deci \& Ryan, 2002), individuals will seek such influence via alternate means. Specifically, certain high-risk activities likely serve a compensatory function for the participant: an opportunity to experience emotion regulation and agency in a way that is perceived as being not readily available in everyday life. Indeed, it has been suggested - but not tested - that such individuals may intentionally seek out situations of chaos, stress and danger so as to demonstrate or reassert their agency and emotional control (Lupton \& Tulloch, 2003; Lyng, 2005). Such dissatisfaction with the status quo is a sine qua non of all human endeavor and all progress. In other words, we need to feel sufficiently dissatisfied with the present state to be motivated to progress toward a future state (Carver \& Scheier, 1998).

If an individual engages in a high-risk activity with the specific (implicit or explicit) aim of experiencing emotion regulation and agency then there is likely an additional benefit from participation. That is, participants may experience a perceived transfer of emotion regulation and agency from the high-risk domain back into important aspects of their everyday life (cf. Woodman et al., 2010). Although such transfer effects have been purported 
to be the aim of engagement in high-risk sport for certain participants (Pain \& Pain, 2005; cf. Smith, 2005), the extent to which any psychological benefits are perceived to transfer into important aspects of participants' everyday life remains unexplored.

When purposeful goal-directed efforts to demonstrate emotion regulation and agency in everyday life are unsuccessful an individual will typically experience negative affect (Wicklund, 1975). When faced with such situations, individuals can award an alternative compensatory goal a higher priority than was previously the case (Sloman, 1987). For this priority to be given, the alternate program of action should reflect the same abstract goal as the "failed" activity but with a greater likelihood of success (Carver \& Scheier, 1998). Thus, the perceived difficulty in experiencing emotion regulation and agency that mountaineers report in important aspects of their everyday life (cf. Woodman et al., 2010) may translate into their compensatory seeking of the experience of emotion regulation and agency in the high-risk domain. However, there are seemingly many compensatory activities that could provide an individual with the experience of emotion regulation and agency. As such, it is important to consider the specificity of risk-takers' difficulty with emotion regulation and diminished agency to understand their motives for seeking emotion regulation and agency specifically in their chosen high-risk domain.

Mountaineers' difficulty with emotion regulation in everyday life appears to be such that they experience a constant, generalized and internalized low-level anxiety (Massumi, 1993); a response to a non-specific threat, the sources of which may be confusing and unclear (Cisler, Olatunji, Feldner, \& Forsyth, 2010). As such, mountaineers are likely unable to identify the origin of their anxiety, express it, or control it effectively (Woodman et al., 2010). The attraction of the high-risk domain is that it enables participants to move from a non-specific, ambiguous and internal anxiety to a specific, identifiable, and externallyderived intense emotion: fear (cf. Castanier, Le Scanff \& Woodman, 2010; Fenichel, 1939). 
Unlike anxiety, fear is a response to a known, external, and definite threat (Sadock \& Sadock, 2007), of which there is an abundance in the high-risk domain. Fear can be an attractive alternative to anxiety since externalized relatively objective threats are more readily interpreted as within an individual's control (Chorpita \& Barlow, 1998) and require explicit rather than implicit emotion regulation (Gyurak, Gross, \& Etkin, 2011). As such, successful emotion regulation can diminish fear (Cisler et al., 2010), which is supported by mountaineers' ardent desire to experience a "freedom from fear" (Lester, 2004, p. 91). Recent research further supports the central role of fear in seeing life in a more positive light after the fearful event (Eskine, Kacinik, \& Prinz, 2012).

Mountaineers' perceived diminished agency appears specific to emotional interpersonal relationships (Lester, 1983; Woodman et al., 2010). As such, an appropriate compensatory activity is not one that provides merely a generic sense of agency. Rather, it must serve the same abstract goal as the "failed" activity, but wherein success is more likely (Taylor \& Hamilton, 1997). Specifically, mountaineering affords the individual an opportunity to disengage temporarily from close interpersonal relationships in everyday life and to engage in a compensatory relationship with the mountains. Interestingly, the mountaineering literature is replete with references that portray the relationship with the mountains as romantic (e.g., Lester, 2004). Interpersonal relationships and the mountains are similar to the degree that both are perceived as chronically difficult and stressful, and reflect a prolonged emotional struggle. The difference between the two relationships is that in mountaineers' interpersonal relationships, the emotions that are engendered are perceived as being dictated and driven by forces outside of their control (Lester, 1983; 2004); in the highrisk domain, the emotions that are engendered are perceived as being dictated and driven by the self as an instinctively acting agent (cf. Lyng, 2005).

If participants engage in a high-risk activity with the specific aim of experiencing 
emotion regulation and agency then they should experience an emotion regulation and agency transfer, albeit temporary, from the high-risk development domain to important aspects of their everyday life (i.e., the target domain; Barnett \& Ceci, 2002, Pain \& Pain, 2005). Similarity between the development domain and the target domain is a critical determinant in maximizing transfer effects (Singley \& Anderson, 1989). Thus, mountaineers' engagement in an intensely emotional and active relationship with the mountains should help to maximize the effective transfer from the high-risk domain to emotional interpersonal relationships.

\section{Purpose of the present research}

The purpose of the present paper is to challenge the view that all high-risk activities are the same and motivated simply by sensation seeking. We aim to examine the different motives that drive participation in two contextually specific high-risk activities - skydiving and mountaineering - from sensation seeking, emotion regulation, and agency perspectives (Studies 2-4). We chose two specific activities that appear to typify either the sensation seeking model (skydiving) or the emotion regulation and agency model (mountaineering) with a view to being able to conduct a thorough investigation of the specific differences between two categories of high-risk activities. This was deemed necessary because many high-risk activities likely share some characteristics of both models and would thus cloud the potential differences between the two theoretical models. Due to the lack of a suitable measure in the existing literature, the initial task was to create a new scale that measured sensation seeking, emotion regulation and agency as motives for participation in a high-risk activity.

\section{Study 1}

Measuring Sensation Seeking. Zuckerman's sensation seeking scale (SSS-V; Zuckerman, 1979) has become practically synonymous with risk-taking research and identifies the disposition, desire, or intention to engage in activities that Zuckerman assumes 
provide unusual, novel, or intense sensations and experiences (Zuckerman, 2008). However, the almost exclusive use of the SSS-V has hampered research in understanding the motives that underlie participation in high-risk activities (e.g., Arnett, 1994). For example, despite what the name suggests, the Thrill and Adventure Seeking (TAS) subscale of the SSS-V does not measure thrill seeking per se. Rather, high TAS scores on the SSS-V reflect participants' elevated propensity or desire to engage in certain high-risk activities (e.g., "I would like to try parachute jumping;" "I often wish I could be a mountain climber"). Given that many highrisk participants already engage in such activities it is tautological and uninformative to report that high-risk participants report high scores on such scales (Llewellyn \& Sanchez, 2008; Slanger \& Rudestam, 1997). Thus, there remains a need for a scale that measures sensation seeking as a motive for participation in high-risk activities.

Measuring Emotion Regulation and Agency. There is currently no measure of emotion regulation and agency motives for participation in activities. To date, researchers have measured participants' emotion regulation and agency via participant observation (Lester, 1983), qualitative inquiry (Woodman et al., 2010), and quantitative examination of constructs that appear to be related to emotion regulation (e.g., alexithymia; Woodman et al., 2010) and agency (e.g., spheres of control; Woodman et al., 2010). Consequently, there remains a need for a scale that measures both emotion regulation and agency as motives for participation in (high-risk) activities.

Development of a new inventory. High-risk participants generally have difficulty in clearly articulating the motives for their behavior (Loewenstein, 2007; Roberts, 1986; Smith, 2005). This is likely because participation is driven by motives that are somewhat implicit. Consequently, explicit item stems such as "I participate because..." were deemed unsuitable for exploring the complex motives that may underpin engagement in high-risk activities. Instead, we determined to assess participants' perceptions of their sensation needs, emotional 
regulation, and agency before participation, their relevant experiences while participating, and the transfer benefits that they experienced as a consequence of their participation. The aim of Study 1 was thus to develop a measure that assessed participants' experience of sensation seeking, emotion regulation and agency at three time points - before, while, and after participating in a high-risk activity - with a view to identifying how participants might differ in the need for sensation, emotion regulation, and agency as a function of their participation timeline.

\section{Method}

Participants. We first sought to develop and refine this three-factor scale by recruiting 295 individuals who participated in a diverse range of sports - both high-risk (e.g., skydiving, mountaineering, extreme skiing, rock climbing) and relatively low-risk (e.g., basketball, hockey, athletics) - and who varied in ability (beginners to professional athletes). The chance to win $£ 20$ (approximately US\$32) on completion of all three online inventories was offered as an incentive. The final samples for each inventory were: before participating, $n=238\left(194\right.$ men, 44 women; $\left.M_{\text {age }}=28.58, S D=9.09 ; M_{\text {years participating }}=9.41, S D=8.63\right)$; while participating, $n=244$ (199 men, 45 women; $M_{\text {age }}=29.31, S D=9.71 ; M_{\text {years participating }}=$ 9.25, $S D=8.34)$; and after participating, $n=238$ (196 men, 42 women; $M_{\mathrm{age}}=28.52, S D=$ 9.03; $\left.M_{\text {years participating }}=9.53, S D=9.03\right)$.

Measures. The initial Sensation seeking, Emotion regulation and Agency Scale (SEAS) comprised three separate inventories: before participating (34 items), while participating (30 items), and after participating (31 items). The items within each inventory reflected the three proposed motivational factors - sensation seeking, emotion regulation and agency - and were developed by the authors on the basis of the theoretical perspective described in the general introduction.

Sensation seeking items were concerned with: the need for sensation before 
participating (e.g., Before participating, I want to get a physical buzz); the experience of sensation while participating (e.g., While participating, I get a rush of chemicals around my body that feels great); and the satisfaction of sensation need after participating (e.g., After participating, I am often buzzing from the adrenaline).

Items pertaining to emotion regulation measured: a difficulty with emotion regulation before participating (e.g., Before participating, the emotional elements of my life are difficult to deal with); the experience of emotion regulation while participating (e.g., While participating, I have to deal with intense emotions); and a sense of emotion regulation after participating (e.g., After participating, I find intense emotions easier to deal with).

Finally, items pertaining to agency measured: a diminished sense of agency before participating (e.g., Before participating, I feel like my life 'belongs' to other people); the experience of agency while participating (e.g., While participating, I am in charge); and a sense of agency after participating (e.g., After participating, I feel better about my ability to bring about important outcomes in my life). Participants responded to each item on a sevenpoint Likert scale from 1 (completely disagree) to 7 (completely agree).

Procedure. Participants completed the survey online (cf. Mangunkusumo et al., 2005). We used software (Qualtrics, 2009) that utilizes cookies and IP address tracking to prevent multiple responses from the same individual in any single study and the same individual from appearing in multiple studies. Participants completed demographic data pertaining to their three favorite participating activities (frequency, duration, ability/grade) and the three SEAS inventories (before, while, and after participating) with regard to their engagement in those activities. Where items said "in my life" participants were asked to think about elements of their life that were important to them (e.g., relationship with a partner, friends, family, and work).

Analyses. Data were analyzed using confirmatory factor analysis partially in an 
exploratory fashion. A model was considered a good fit to the data if the Comparative Fit Index (CFI, Bentler, 1990) and the Non-Normed Fit Index (NNFI, Tucker \& Lewis, 1973) were greater than or equal to .95; the Root Mean Square Residual (RMSEA, Steiger \& Lind, 1980) was less than or equal to .06 ( $p>.05)$; the Standardized Root Mean Square Residual (SRMR, Bentler, 1990) was less than or equal to .08; and the Satorra-Bentler (S-B) $\chi^{2} / \mathrm{df}$ ratio was less than 2.00 .

\section{Results}

Before participating inventory. Each of the three factors - sensation seeking (SS), emotion regulation (ER) and agency (AG) - was initially examined individually in order to retain only those items that were good indicators of their underlying latent variable (cf. Jöreskog, 1993). Post-hoc model modifications were carried out by examination of the standardized residuals, factor loadings, modification indices for theta-delta, and theoretical considerations. Single-factor CFA results indicated that the fit of the models to the data could be significantly improved by removing certain items. This iterative process led to the retention of six items in each factor, which revealed a good fit for the three-factor before participating full-model (see Table 1). Factor-factor correlations supported the discriminant validity between SS-ER (.08) and SS-AG (.12). Since the factor-factor correlation between ER-AG was moderately high (.83) we conducted a Satorra \& Bentler (2001) scaled difference $\chi^{2}$ test $\left(S-B \chi^{2}\right.$ diff $)$ on the three-factor model $(\mathrm{SS} ; \mathrm{ER} ; \mathrm{AG})$ and a re-specified two-factor model (SS; ER \& AG). This test supported the discriminant validity of the ER and AG factors $\left(S-B \chi^{2}\right.$ diff $\left.(1)=65.23, p<.001\right)$. The item-factor loadings for each subscale are displayed in Table 1.

While participating inventory. The same testing procedure was used as detailed above. The iterative process revealed a good fit for a three-factor 18-item while participating full-model. Factor-factor correlations supported the discriminant validity between SS-ER 
(.59) and ER-AG (.59). Although the SS-AG correlation was again moderately high (.85) a Satorra-Bentler scaled difference $\chi^{2}$ test supported the discriminant validity of the SS and AG factors $\left(S-B \chi^{2}\right.$ diff $\left.(1)=217.30, p<0.01\right)$. The item-factor loadings for each subscale are displayed in Table 2 .

After participating inventory. The same procedures as described above yielded a good-fitting three-factor 18-item after participating full model: Factor-factor correlations supported the discriminant validity between SS-ER (.58) and SS-AG (.52). Again, although the ER-AG correlation was very high (.97) a Satorra-Bentler scaled difference $\chi^{2}$ test supported the discriminant validity of the ER and AG factors $\left(S-B \chi^{2}\right.$ diff $\left.(1)=5.39, p<0.05\right)$. Nonetheless, .97 remains a large correlation that is worthy of attention. The item-factor loadings for each subscale are displayed in Table 3.

\section{Scale Confirmation}

Using the same method as described previously, we recruited 296 new participants to confirm the factor structure of the SEAS and to clarify the after participating factor structure. The diversity of activities represented, and the participant experience therein, closely mirrored that described previously. The final samples for each inventory were: before participating, $n=247$ (199 men, 48 women; $\left.M_{\mathrm{age}}=28.96, S D=9.78\right)$; while participating, $n=$ 261 (212 men, 49 women; $\left.M_{\text {age }}=29.56, S D=10.44\right)$; after participating, $n=245$ (192 men, 53 women; $\left.M_{\text {age }}=29.50, S D=10.16\right)$. The procedure was the same as described previously and the fit indices replicated the good fit of each of the three-factor 18-item models (see Tables 13). Also, factor-factor correlations supported the discriminant validity of the three-factor model for the before participating model $(\mathrm{SS}-\mathrm{AG}=.08 ; \mathrm{SS}-\mathrm{ER}=.17 ; \mathrm{ER}-\mathrm{AG}=.80)$ and for the while participating model $(\mathrm{SS}-\mathrm{AG}=.49 ; \mathrm{SS}-\mathrm{ER}=.71 ; \mathrm{ER}-\mathrm{AG}=.57)$. For the after participating inventory, the factor-factor correlations also supported the discriminant validity between SS-ER (.49) and SS-AG (.41). However, as with the first sample, the factor-factor 
correlation between ER-AG was high (.99). A Satorra-Bentler scaled difference $\chi^{2}$ test confirmed that constraining the correlations between factors to unity did not significantly impair the fit $\left(S-B \chi^{2}\right.$ diff $\left.(1)=.45, p>0.50\right)$. The re-specified two-factor model (SS; ER \& AG) demonstrated a good fit (see Table 3).

\section{Discussion}

The aim of Study 1 was to develop a new scale - the SEAS - to measure sensation seeking, emotion regulation and agency as motives for participating in a high-risk activity. The SEAS comprises three inter-related inventories that are completed retrospectively of participation and address percepts before participating, while participating, and after participating. The full models fit the data well and there was clear support for the three-factor structure - sensation seeking, emotion regulation and agency - in both the before participating and while participating inventories.

Although the three-factor structure was also replicated in the after participating inventory for both samples, the factor-factor correlation between emotion regulation and agency was consistently high. Consequently the three-factor model - sensation seeking, emotion regulation, and agency - was rejected in favor of a two-factor model measuring sensation seeking and agentic emotion regulation. The constructs of agency and emotion regulation are somewhat conceptually interdependent since effective emotion regulation involves intentionally influencing one's affective state and presumes active contributions to one's emotional experience (cf. Gross, 1998). In other words, the emotionally regulated individual is an agent in that regulation process (Woodman et al., 2010) and, as such, moderate correlations between agency and emotion regulation were expected.

\section{Study 2}

In Study 2 we sought to use the SEAS to discriminate the motives of mountaineers, skydivers, and a low-risk control group. Despite the strong sensation seeking focus, 
skydiving clearly also requires a degree of agency and emotion regulation during the activity. Put simply, the skydiver who jumps from an airplane and demonstrates a complete failure to display agency and to regulate emotions will die. However, the emotion regulation and agency demands on the skydiver (e.g., regulating fear, controlling the body in free fall, opening the canopy) are limited, both in frequency and duration, compared to the same demands on the mountaineer. In the mountaineering domain, self-governing autonomous action and regulation of intense emotions is a requisite for survival throughout each day for days and weeks on end. As such, mountaineers should experience greater agentic and emotion regulation transfer effects than skydivers.

Sensation seeking hypothesis. Skydivers, unlike mountaineers, are motivated by the sensation function of participation. Specifically, compared to both mountaineers and low-risk controls, skydivers will score significantly higher on: the need for sensation before participating; the experience of sensation while participating; and the satisfaction of sensation need after participating. Mountaineers and low-risk controls will not differ.

Agency and emotion regulation hypothesis. Mountaineers, unlike skydivers, are motivated by the emotion regulation and agency function of participation. Specifically, compared to both skydivers and low-risk controls, mountaineers will score significantly higher on: difficulty with emotion regulation and diminished agency before participating; the experience of emotion regulation and experience of agency while participating; and agentic emotion regulation after participating. Given that a degree of emotion regulation and agentic action is a requisite for survival in the high-risk domain, we further hypothesize that skydivers will have a greater experience of emotion regulation and experience of agency than participants in low-risk activities.

\section{Method}

Participants. Study 2 participants were drawn from the Study 1 sample pools based 
on the demographic information provided therein. Given that individuals who are professional high-risk instructors have been shown to display significantly different risktaking profiles to those engaged in high-risk activities for recreational purposes (Cazenave, Le Scanff, \& Woodman, 2007), we removed professional instructors from both the skydiving and mountaineering samples.

Skydivers were operationalized as individuals who had completed a minimum of 24 jumps in the previous year. Thirty-five individuals satisfied these criteria $\left(M_{\text {years participation }}=\right.$ $\left.4.54, S D=6.94 ; M_{\text {skydives } / \text { year }}=113.46, S D=94.13\right)$.

Mountaineers were operationalized as individuals who went on expeditions for at least 15 days during an average year. Additionally, mountaineers had to have completed at least one expedition in the previous year that lasted a minimum of five days, at a minimum grade of AD- (International French Adjectival System) or equivalent. Twenty-eight individuals satisfied these criteria $\left(M_{\text {years participation }}=17.89, S D=13.34 ; M_{\text {mountaineering days/year }}=\right.$ $50.82, S D=48.83)$.

Low-risk sport participants were defined as those individuals who had participated in low-risk sport (e.g., soccer, running, golf, basketball, hockey, etc.) at least 20 times in the previous year. Additionally, participants had to have not participated in activities defined as high-risk (e.g., rock climbing, paragliding, surfing) more than three times in the previous year. In order to produce an orthogonal design, we randomly selected 28 (14 from each sample) of the 53 control participants who satisfied these criteria $\left(M_{\text {years participation }}=9.35, S D\right.$ $\left.=6.60 ; M_{\text {participations/year }}=95.00, S D=60.19\right)$.

The final samples comprised 35 experienced skydivers $\left(29\right.$ men, 6 women; $M_{\mathrm{age}}=$ 28.71, $S D=9.51), 28$ mountaineers $\left(23\right.$ men, 5 women; $\left.M_{\mathrm{age}}=38.04, S D=15.61\right)$ and 28 low-risk sport participants (17 men, 11 women; $\left.M_{\text {age }}=26.14, S D=6.58\right)$.

Procedure. No additional data were required beyond those collected in Study 1. 
Analyses. Each inventory (before, while, after) contained three dependent variables (sensation seeking, emotion regulation and agency) on which the three groups (mountaineers, skydivers, controls) were compared. Univariate analyses were preferred to multivariate analyses because the dependent variables were not considered as linear combinations of each other. Given that emotion regulation and agency were hypothesized to be the primary motives for mountaineers' engagement in their activity while being only a correlate of skydivers' sensation seeking motive, we used sensation seeking as a covariate when examining the extent to which the three groups differed in the experience of emotion regulation and agency.

\section{Results}

Sensation seeking. ANOVAs and Bonferroni tests revealed that skydivers' motives were consistently higher in sensation seeking across the timeline. Specifically, skydivers reported: a significantly higher need for sensation than both mountaineers $(p<.05)$ and controls $(p<.01)$, who did not differ from each other $(p>.50)$; a significantly greater experience of sensation than both mountaineers $(p<.05)$ and controls $(p<.001)$, who did not differ from each other ( $p=.17)$; and a significantly greater satisfaction of sensation need than both mountaineers $(p<.05)$ and controls $(p<.001)$, who did not differ from each other $(p>$ .50). The results for each analysis are reported in Table 4.

Emotion regulation. ANCOVAs and Bryant Paulson tests revealed no significant difference between the groups in difficulty with emotion regulation before participating. While participating, mountaineers and skydivers reported a greater experience of emotion regulation than the control group $(p<.05)$ but did not significantly differ from each other. ${ }^{2}$

Agency. ANCOVAs and Bryant Paulson tests revealed no significant difference between the groups in diminished agency before participating. While participating,

\footnotetext{
${ }^{2}$ The assumption of homogeneity of regression slopes was marginally violated $(p=.05)$
} 
mountaineers and skydivers reported a greater experience of agency than the control group ( $p$ $<.05)$ but did not significantly differ from each other.

Transfer. ANCOVA and Bryant Paulson tests revealed that mountaineers reported significantly greater agentic emotion regulation transfer than both skydivers $(p<.05)$ and the control group $(p<.05)$, who did not differ from each another.

\section{Discussion}

The aim of Study 2 was to demonstrate that different risk-taking activities serve different motivational goals.

Sensation seeking. As hypothesized, skydivers displayed a greater need for sensation (before), a greater experience of sensation (while), and a greater satisfaction of sensation need (after) than both mountaineers and low-risk controls, who were undifferentiated on all the sensation seeking factors. These results are the first clear indication that the consideration of high-risk activity participants as a homogeneous sensation seeking group (Zuckerman, 2007) is an erroneous position. Indeed, the present study is the first empirical test, and subsequent rebuttal, of that uniform sensation seeking position.

Emotion regulation and agency. As hypothesized mountaineers reported deriving an agentic emotion regulation transfer benefit after participation that skydivers and low-risk controls do not experience. These results provide the first empirical evidence that some highrisk activities can provide a beneficial agentic emotion regulation transfer from the high-risk domain back into important aspects of everyday life.

Although the beneficial transfer of agency and emotion regulation back into everyday life was clear, the emotion regulation and agency effects in the while participating and before participating data were rather less clear. As hypothesized, compared to the control group, both mountaineers and skydivers reported a greater experience of emotion regulation and experience of agency during the activity. However, the hypothesized differences between the 
two types of risk-taking behavior did not emerge as significant. This result suggests that agentic action may be a requisite element of successful participation in the high-risk domain, regardless of the considerable contextual differences that exist between high-risk activities.

The lack of emotion regulation difference between the two high-risk groups was somewhat more surprising, however, because highly regulated emotions appear somewhat incongruent with skydivers' significantly elevated experience of sensation while participating. That is, a skydiver with high emotion regulation would likely experience jumping from an airplane as lacking in "thrill” (cf. Campos, Frankel, \& Camras, 2004). Thus, we maintain that skydivers, unlike mountaineers, desire only to regulate their emotions to the extent that is necessary to ensure safe pursuit of their activity. Given this theoretical position - as well as the possibility of a type II error due to the relatively small sample size, and the violation of the assumption of homogeneity of regression slopes - Study 2 warrants replication, with a larger sample size.

Mountaineers also did not report significantly greater difficulty with emotion regulation or diminished agency before participating than skydivers or controls. There are two important considerations regarding this null finding. First, the lack of differences may be an artifact of the before inventory. That is, when considering before participating, participants may have considered only those moments immediately before participation. Such moments are associated with the pending (high-risk) experience rather than participants' everyday life in the lead-up to the high-risk experience. However, the theoretical rationale for the mountaineers' difficulty with agency and emotion regulation is thought to be more a reflection of their everyday life; that is, the difficulty is more between participations (when they have not participated for a significant period of time) than immediately before participating. We address this limitation in Study 3.

The second potential explanation for the null differences in the before participating 
data resides in participants' perceptions of what it means to feel effective, in agentic and emotion regulation terms. We originally hypothesized that mountaineers would perceive that they have greater difficulty with emotion regulation and diminished agency in everyday life and the available evidence clearly points to such a struggle with the self in everyday life (Kirkpatrick, 2011; Lester, 2004). As such the important inter-participations difficulty for mountaineers is likely not simply in relation to other individuals, but also in relation to their degree of agency and emotion regulation compared to how they perceive that they ought to feel. Mountaineers have previously demonstrated a high need for control (Ewert, 1994), autonomy (Lester, 1983), self-determination (Frederick \& Ryan, 1995), enjoyment of leadership roles (cf. Leon et al., 1989; Lester, 1983), and assertive individuality and dominance (Egan \& Stelmack, 2003), particularly in interpersonal relationships (Lester, 1983; Woodman et al., 2010). These characteristics may reflect an exaggerated expectancy of the emotion regulation and agency that such individuals perceive that they ought to experience as part of everyday life. According to such a position, mountaineers will seek out the experience of agency and emotion regulation in the high-risk domain because they desire to elevate agency and emotion regulation to a level that they feel is more normal for them. This issue is addressed and tested in Study 4.

Although the SEAS appears to possess some discriminant validity, there is clearly a need to demonstrate concurrent validity also. For example, one would expect the SEAS factors to correlate moderately with established measures of sensation seeking, emotion regulation, and agency. Furthermore, one would expect them to correlate moderately with certain aspects of personality. Specifically, the need for sensation should correlate with extraversion (cf. Breivik, Roth, \& Jørgensen, 1998) and - given the emotional difficulty associated with a lack of emotion regulation and agency - the difficulty with emotion regulation and diminished agency factors should correlate negatively with emotional stability. 
Finally, given our critique of the misuse of traditional sensation seeking measures, there is also a need to demonstrate that the SEAS can discriminate the motives for high-risk activities where more traditional measures cannot. All these issues are addressed in Study 3.

\section{Study 3}

The aim of Study 3 was fourfold. First, by modifying the instruction set for the before participating inventory (from before participating to between participations) we aimed to test more precisely the hypothesis that mountaineers will experience significantly greater difficulty with emotion regulation and diminished agency - between participations.

Second, we aimed to test the concurrent validity of the SEAS against established measures of sensation seeking, agency, emotion regulation, as well as personality. The third aim was to replicate the hypothesis and finding from Study 2 that sensation seeking is at the core of the motive for skydiving but is not a motive for mountaineers. Although it is theoretically misguided to expect Zuckerman's (1979) SSS-V to differentiate risk-taking groups on the basis of sensation seeking as a motive for behavior, this expectation remains to be dismissed empirically. As such, we aim to demonstrate empirically that: (a) the SSS-V is incapable of discriminating risk-taking groups on the basis of sensation seeking; (b) the SEAS discriminates risk-taking groups on the basis of need for sensation.

Finally, we aimed to allay concerns that the mountaineers may have a naïve in-group perception of what it means to be a mountaineer by testing for group differences in social desirability.

\section{Method}

Participants. Participants were recruited and operationalized as previously. The groups were: 41 skydivers (36 men, 5 women; $M_{\mathrm{age}}=29.95, S D=10.36 ; M_{\text {years participation }}=$ $\left.2.56, S D=2.55 ; M_{\text {total jumps }}=122.07, S D=63.23\right) ; 39$ mountaineers $\left(35\right.$ men, 4 women; $M_{\text {age }}$ $=30.36, S D=7.60 ; M_{\text {years participation }}=8.77, S D=6.31 ; M_{\text {expedition duration }}=19.56$ days, $S D=$ 
$\left.9.45 ; M_{\text {mountaineering days in previous year }}=38.74, S D=34.45\right) ;$ and 32 low-risk sport participants $(31$ men, 1 woman; $M_{\text {age }}=35.53, S D=13.70 ; M_{\text {years participation }}=10.87, S D=8.89 ; M_{\text {weeks in previous }}$ year that included sport participation $=39.78, S D=20.02$ ).

\section{Measures}

Motives for high-risk activities. Participants completed the previously validated before participating SEAS with one modification: Instead of asking participants to rate their need for sensation and their difficulty with agency and emotion regulation before participating, we asked them to rate these constructs in relation to how they feel between participations (When you have not participated for a significant period). This was to better capture participants' experience of everyday life when they have not been participating in their high-risk activity. The inventory introduction emphasized that participants should define for themselves what they considered to be a significant period. Apart from this instruction, the inventory and the items remained unchanged.

Sensation Seeking. The Sensation Seeking Scale-V (SSS-V; Zuckerman, 1979) comprises 10 forced-choice items for each of the four factors of Thrill and Adventure Seeking, Experience Seeking, Disinhibition, and Boredom Susceptibility. The SSS-V is the most widely used measure of sensation seeking (see Zuckerman, 2007).

Emotion Regulation. We used the subscale of ability to regulate one's own emotions from the Emotional Intelligence Scale (Tett, Fox, \& Wang, 2005; e.g., I can keep myself calm even in highly stressful situations). This subscale comprises 12 items scored on a Likert scale from 1 (Disagree very much) to 6 (Agree very much).

Agency. We used the Lack of Mastery subscale from Pearlin and Schooler's (1978) inventory, which comprises seven items (e.g., I have little control over the things that happen to me) scored on a Likert scale from 1 (Strongly disagree) to 5 (Strongly agree). 
Personality. The Ten-item Personality Inventory (Gosling, Rentfrow, \& Swann, 2003) measures the big five personality constructs of extraversion, conscientiousness, openness to new experience, emotional stability, and agreeableness, and comprises two items for each of the five factors, scored on a Likert scale from 1 (Disagree strongly) to 7 (Agree strongly).

Social Desirability. We used the Balanced Inventory of Desirable Responding (Paulhus, 1994) to measure social desirability. This inventory comprises 20 items measuring self-deceptive enhancement (e.g., I never regret my decisions) and 20 items measuring impression management (e.g., I never cover up my mistakes) scored on a Likert scale from 1 (not true) to 7 (very true).

Procedure. The same procedure was followed as that described previously except for the additional measures.

\section{Results}

The correlations are displayed in Table 5. As expected, the need for sensation correlated with sensation seeking; the difficulty with emotion regulation correlated with emotion regulation; and diminished agency correlated with lack of mastery. Furthermore, the need for sensation was correlated with extraversion, and both diminished agency and difficulty with emotional regulation were negatively correlated with the personality trait of emotional stability.

The groups were not discriminated on the basis of either of the SEAS factors of difficulty with emotion regulation or diminished agency alone (see Table 6), which replicates the results of Study 2 and confirms that these null effects were not simply an artifact of the instruction wording (i.e., before participating or between participations).

As expected, ANOVAs revealed skydivers demonstrated a significantly greater need for sensation than mountaineers $(p<.001)$. Importantly, and unsurprisingly, the total SSS-V 
and each of its subscales were unsuccessful in discriminating between the two high-risk activities $(p s>.50)$. ANCOVA and Bryant Paulson tests revealed that, controlling for the SSS-V sensation seeking, the SEAS need for sensation difference between the high-risk activities groups remained. Specifically, skydivers demonstrated a significantly greater need for sensation than mountaineers $(p<.01)$. None of the big five personality factors discriminated the two high-risk activities (see Table 6). Finally, a multiple logistic regression analysis revealed that the combined SSS-V subscales were unable to predict high-risk activity group (i.e., mountaineer or skydiver) while need for sensation significantly predicted group membership over and above the SSS-V ( $p=.002$; see Table 7). All tests for multicollinearity were within acceptable limits.

There were no significant impression management social desirability differences between the groups. Although skydivers reported significantly elevated self-deception enhancement compared to controls $(p<.01)$, they did not differ from mountaineers $(p>.50)$. Finally, when controlling for self-deception enhancement, ANCOVA and Bryant Paulson tests revealed that skydivers continued to report significantly greater need for sensation than mountaineers $(p<.01)$ and controls $(p<.01)$.

\section{Discussion}

In support of the concurrent validity of the SEAS and as hypothesized, the SEAS factors correlated with established measures of sensation seeking, emotion regulation, and agency, as well as personality measures. The results also demonstrated that the need for sensation differences between the two high-risk activities cannot be explained by social desirability differences between these groups. Interestingly, the personality construct of conscientiousness discriminated the mountaineers from the control group and provides further evidence that high-risk activities cannot be classified as uniform hedonic behavior.

Finally, Study 3 replicated the finding that sensation seeking is at the core of the 
motive for skydiving but is not a motive for mountaineers. Specifically, as in Study 2, the SEAS was successful in demonstrating that the need for sensation is the principal motive for high-risk activities such as skydiving, but not for high-risk activities such as mountaineering. Importantly, the results from the present study align with a large body of research (see Zuckerman, 2007) that reveals that the SSS-V does not discriminate between participants of high-risk sports. Thus, the SEAS is superior to the SSS-V for the examination of the specific sensation seeking motive for high-risk activities and any such differences between them.

\section{Study 4}

The aim of Study 4 was twofold. First, we aimed to retest the hypotheses from Study 2 using a larger sample. Second and of more central interest, given that mountaineers are thought to have greater expectations about agency and emotion regulation experience in everyday life, we aimed to test the multivariate hypothesis that mountaineers will have greater difficulty with emotion regulation and greater emotion regulation expectancy than both skydivers and low-risk controls. Similarly, we aimed to test the multivariate hypothesis that mountaineers will have diminished agency and enhanced agency expectancy than both skydivers and low-risk controls.

\section{Method}

Participants. Participants were recruited and operationalized as previously. The groups were: 100 skydivers $\left(68\right.$ men, 32 women; $M_{\text {age }}=29.19, S D=9.01 ; M_{\text {years participation }}=$ $\left.4.12, S D=4.21 ; M_{\text {jumps in previous year }}=70.71, S D=49.16\right) ; 46$ mountaineers $(37$ men, 9 women; $M_{\text {age }}=30.24, S D=8.61 ; M_{\text {years participation }}=9.63, S D=8.11 ; M_{\text {expedition duration }}=17.60$ days, $S D=12.72 ; M_{\text {mountaineering days in previous year }}=36.83, S D=27.81$ ); and 47 low-risk sport participants (29 men, 18 women; $M_{\text {age }}=29.04, S D=12.33 ; M_{\text {years participation }}=14.64, S D=$ $\left.7.69 ; M_{\text {sport days in previous year }} 184.28, S D=125.27\right)$.

Measures and Procedure. Participants completed demographic data and the SEAS 
as in Study 2. The change of wording from before participating to between participations, implemented in Study 3, was maintained. The modification was the addition of a Likert scale in the between participations inventory to measure participants' expectancy regarding their experience of emotion regulation and agency, between bouts of participation. This was to enable us to test the multivariate hypothesis. We clarified this scale further by asking participants to consider the phrase, "are you agitated by the way things are or are you quite happy to feel the way you do?" Responses were recorded on a seven-point Likert scale from 1 (It's OK to feel like this) to 7 (I ought not to feel like this).

\section{Results}

Sensation seeking. ANOVA and Bonferroni tests replicated the findings from Study 2. That is, skydivers reported: a significantly greater need for sensation than both mountaineers $(p<.05)$ and controls $(p<.05)$, who did not differ from one another $(p>.50)$; a significantly greater experience of sensation than both mountaineers $(p<.001)$ and controls $(p<.01)$, who did not differ from one another $(p>.50)$; and a significantly greater satisfaction of sensation need than both mountaineers $(p<.001)$ and controls $(p<.05)$, who did not differ $(p>.50)$. The details of each analysis are reported in Table 8 .

Emotion Regulation difficulty and expectancy. ANCOVAs and Bryant Paulson tests revealed that mountaineers reported significantly greater experience of emotion regulation than both skydivers $(p<.05)$ and controls $(p<.05)$ during participation. Furthermore, skydivers reported significantly greater experience of emotion regulation than controls $(p<.05)$. This result confirms the original hypothesis from Study 2.

Univariate ANOVAs replicated the null hypothesis from Study 3 as expected: there were no significant differences between the groups in difficulty with emotion regulation between participations, $F(2,190)=2.60, p=.08$. We thus proceeded with tests of the multivariate hypotheses. MANOVA revealed a significant difference in difficulty with 
emotion regulation and emotion regulation expectancy between skydivers, mountaineers and controls (see Table 8). Discriminant function analysis (DFA) yielded two discriminant functions. The first generated function - accounting for $94.4 \%$ of the total between-groups variability - revealed that perceptions of emotion regulation between participations discriminated between the mountaineers, skydivers, and controls, Wilks' $\Lambda=0.95, \chi^{2}(4, n=$ $193)=10.63, p<.05$. The standardized structure coefficients for the first discriminant function revealed that both variables made a significant contribution to the discriminant function. However, emotion regulation expectancy $(r=1.00)$ made the greatest contribution to the discriminant function, followed by difficulty with emotion regulation $(r=.69)$. Examination of the discriminant function at group centroids revealed that mountaineers $(.37)$ had a higher expectancy of emotion regulation and greater difficulty with emotion regulation than both the skydivers (-.19) and controls (.05), who were not discriminated from each other.

Agency difficulty and expectancy. ANCOVA revealed that both mountaineers and skydivers reported significantly greater experience of agency than the control group $(p<.05)$ but did not significantly differ from one another.

Univariate ANOVAs replicated the null hypothesis from Study 3 as expected: there were no significant differences between the groups in diminished agency between participations, $F(2,190)=0.97, p=.38$. We thus proceeded with tests of the multivariate hypotheses. MANOVA revealed a significant multivariate difference in diminished agency and agency expectancy between the groups (see Table 8). Discriminant function analysis again yielded two discriminant functions, but the first generated function accounted for $100 \%$ of the total between-groups variability, which revealed that perceptions of agency between participations discriminated between mountaineers, skydivers, and controls, Wilks' $\Lambda=0.95$, $\chi^{2}(4, n=193)=10.57, p<.05$. The standardized structure coefficients for the first discriminant function suggested that both variables made a significant contribution to the 
discriminant function. However, agency expectancy (.98) made the greatest contribution to the discriminant function, followed by diminished agency (.42). Examination of the discriminant function at group centroids revealed that mountaineers (.43) had a greater expectation of agency and a diminished sense of agency than both the skydivers (-.13) and controls (-.14), who were not discriminated from each other.

Transfer. ANCOVA and Bryant Paulson test confirmed that the difference between the groups in agentic emotion regulation remained significant after controlling for satisfaction of sensation need, thus confirming the hypothesis and finding from Study 2: Mountaineers reported significantly greater agentic emotion regulation than both skydivers ( $p$ $<.05)$ and control groups $(p<.05)$, who did not differ from one another $(p>.05)$.

\section{Discussion}

\section{Replication of Study 2 results}

Sensation Seeking. The present study replicated all the sensation seeking findings from Study 2. Specifically, skydivers reported significantly greater need for sensation, experience of sensation and satisfaction of sensation need than both mountaineers and lowrisk controls. Although some high-risk activities are clearly motivated by sensation seeking, others clearly are not motivated by sensation seeking.

Emotion Regulation and Agency. Study 4 replicated the results from Study 2: Mountaineers derive an agentic emotion regulation transfer benefit after participation that skydivers and low-risk controls do not experience. Study 4 also provided support for the hypothesis that mountaineers have a significantly greater experience of emotion regulation than skydivers while participating. This suggests that mountaineers, unlike skydivers, are primarily motivated to seek out the experience of emotion regulation in the high-risk domain. Furthermore, as hypothesized, Study 4 demonstrated that a degree of emotion regulation is also experienced by skydivers thus suggesting that even participation in high-sensation high- 
risk sports requires an element of emotion regulation. However, since overly regulated emotions may attenuate the in situ experience of sensation (Campos et al., 2004), skydivers likely aim to regulate their emotions only to the degree that it enables them to operate safely in the high-risk domain. Conversely, the experience of emotion regulation is central to mountaineers' engagement with their activity.

Consistent with Study 2, Study 4 revealed that the experience of agency is an important facet of participation in high-risk sport. Indeed, both mountaineers and skydivers reported a significantly greater experience of agency than low-risk controls, and did not significantly differ from one another. This result consistently contrasts with the initial hypothesis that stated that mountaineers would experience greater agency than skydivers while participating. We interpret this consistent result as a reflection of the need for skydivers to deploy agentic action with a view to decreasing the likelihood of error, which could be potentially fatal. Importantly, agency in this context does not detract from the experience of sensation.

Study 4 confirmed the hypothesis and finding that only mountaineers glean a positive agentic emotion regulation transfer effect from the high-risk domain back into important aspects of everyday life. As in Study 2, mountaineers reported significantly elevated agentic emotion regulation compared to both skydivers and controls, who did not differ. Despite both mountaineers and skydivers undergoing a statistically similar experience of agency while participating, as in Study 2, skydivers did not experience a positive agentic emotion regulation transfer effect. Indeed, as proposed throughout, this is likely due to the experience of agency merely being a requisite for successful engagement with the high-risk domain rather than a motive for engagement. Furthermore, since skydiving is of relatively short duration, the associated experience of agency is likely too brief to provide any meaningful transfer of agentic emotion regulation into everyday life. Thus, future research that 
establishes whether there is an optimum participatory duration for maximizing transfer effects would be worthwhile. Additionally, it would be worthwhile to investigate whether there is a limit of constancy and intensity of the agentic and emotional challenges faced during participation below which there is likely to be no agentic emotion regulation transfer effect.

\section{Great expectations}

We added an expectancy scale with a view to testing the hypothesis that it is the combination of mountaineers' greater expectancy of agency and emotion regulation and their difficulty with agency and emotion regulation in everyday life that is the primary motivation for participation. The multivariate combination of expectancy and difficulty in relation to both agency and emotion regulation successfully discriminated the groups, with expectancy being consistently the most important discriminator. That is, mountaineers had a higher expectation of emotion regulation and a greater difficulty with emotion regulation than both skydivers and controls. Thus, the lack of support for the uni-dimensional difficulty with emotion regulation and diminished agency hypotheses in Study 2 was an artifact of not considering mountaineers' greater expectations of what degree of emotion regulation and agency they feel they ought to experience in life.

High-risk activities, as exemplified here by mountaineering, can thus be motivated more by greater expectations of both emotion regulation and agency than by a greater difficulty with emotion regulation or a diminished sense of agency per se. The results provide the first evidence that some high-risk participants actively engage in the high-risk domain in order to glean an experience of agency and emotion regulation that satisfies a higher-thannormal perception of what life should provide in those terms.

In the context of the mountaineer, the attractiveness and function of the high-risk domain is that it provides the individual with a domain that physically challenges the limits of 
the self in a way that is not readily available in even the most challenging of normative everyday situations, and where success requires a degree of emotion regulation and agency that is consistent with such a challenge. Based on Shackleton's journals and on interviews with the surviving members of the failed 1914 expedition to the South Pole, Lansing (1959) noted that it was only during Antarctic expeditions that Shackleton found "a burden which challenged every atom of his strength", whereas in everyday life, "Shackleton's tremendous capacity for boldness and daring found almost nothing worthy of its pulling power" (p. 13). Once mountaineers have "enjoyed" a prolonged and difficult test of their agency and emotion regulation ability, they will feel more aligned with the agency and emotional experience that they feel ought to pervade their everyday life.

\section{General Discussion}

The aim of the present research was twofold: (a) to challenge the widely held view that high-risk participants can be considered a homogenous sensation seeking group; and (b) to understand the underlying motives for high-risk long-duration low-sensation activities such as mountaineering. A measure of sensation seeking, emotion regulation and agency as motives for participation did not exist before this research. As such, we first developed the measure and then tested the hypotheses using that measure.

Study 1 charted the creation and initial validation of the Sensation seeking, Emotion regulation, and Agency Scale (SEAS), which comprises three inter-related inventories, completed retrospectively in relation to percepts of between participations, while participating, and after participating. The three-factor structure (Sensation seeking, Emotion regulation, Agency) was confirmed for the between and while participating inventories and rejected in favor of a two-factor structure (Sensation seeking; Agentic emotion regulation) for the after participating inventory. In Studies 2-4 we implemented the SEAS to test the hypothesized differential motives of mountaineers, skydivers, and low-risk controls. Study 3 
confirmed that these differences could not be attributed to the established measure of sensation seeking.

The present research demonstrates for the first time that there exist different motives for what has been long considered a single category of voluntary risk-taking. Some risktakers (e.g., skydivers) are motivated by the sensation rewards of their activity, and others (e.g., mountaineers) are motivated by the agentic emotion regulation processes of their activity. This latter motivation is especially informative, as it suggests that risk-takers can be motivated by the possibility of a better future state through an elevated expectancy of their intra-personal and inter-personal life. In such cases, the compensatory function of the highrisk domain is that individuals expect to experience greater emotion regulation and agency during their high-risk activity compared to their other life domains. Finally, and importantly for understanding the perceived benefits of engaging with the high-risk domain, the agentic emotion regulation that is enjoyed post-participation suggests that such benefits are perceived to transfer to other important aspects of everyday life. In other words, by being an agent of their emotion regulation in a high-stress environment for a prolonged period of time, individuals feel better able to agentically regulate their emotions in other prolonged highstress environments that they face in everyday life (cf. Woodman et al., 2010). This is important because such a process suggests that individuals can learn from the high-risk environment and transfer their coping skills back into their everyday life.

High-risk activities and high-risk sports in particular have received minimal attention from personality theorists, likely because they have long been perceived simply as a single category of sensation seeking, much like substance abuse or sexual promiscuity. The present research opens up the possibility for researchers to explore the potential considerable lessons that might be learned, and the benefits that might be gleaned, from understanding the processes that underpin the engagement in high-risk sports. Importantly, risk-taking in the 
present research involves risk that is very much personal. That is, these are not roulette-style caution-to-the-wind risks that implicate little of the person; these are, literally, full-bodied risks that engage and risk the person's life. The present research also stands to inform research on the potential mechanisms that might underlie engaging with outdoor activities, most of which has revealed simply that such activities can have a positive effect on selfconcept (e.g., Hattie, Marsh, Neil, \& Richards, 1997). The processes of emotion regulation and agency could explain such a benefit, although this clearly warrants research attention.

\section{Great Expectations}

Mountaineers' greater emotion regulation and agency expectancies of everyday life are a significant step forward in understanding the motivation that drives individuals' repeated striving for higher and harder achievements. It appears that such individuals are less satisfied with their lot and seek in the high-risk domain a means of achieving more from life. Individuals with such high expectations of themselves likely stand to have either a very fulfilling life or a very unfulfilling life with little in the way of achievement middle ground. That is, individuals who strive for ever-higher (metaphorical and sometimes literal) ground will either achieve such aspirations or will fall short, which could lead to two very divergent life paths. The history of Mount Everest and two of its most celebrated climbers provides a striking illustration of these potential divergent paths.

Sir Edmund Hillary and Sherpa Tenzing Norgay were the first people to summit Mount Everest in 1953, 29 years after George Mallory's fateful attempt. Hillary's significant post-mountaineering accomplishments suggest that his positive goal striving and expectations of life extended far beyond the mountaineering domain. For example, Hillary became the first person to reach the North pole, the South pole, and the summit of Everest; he subsequently became New Zealand high commissioner to India (Johnston, 2008). He has since been named by Time magazine as one of the 100 most influential people of the 20th century. Hillary's 
example illustrates that risk-takers' high expectations of life can result in a very fulfilling life.

There is, however, a darker side to such high expectations in this domain. For example, there are a plethora of cases of mountaineers' depression and alcoholism in the literature. Accounts of Tenzing Norgay’s (Hillary's Everest climbing partner) life certainly describe an uncompromising pursuit of excellence, which, like Hilary, continued into other life spheres - but with mixed success. For example, although Norgay became director of the Himalayan Mountaineering Institute (Douglas, 2003), he perceived that forces outside of his control (e.g., work and family) impinged on his ambitions. For much of his life Norgay had been a moderate drinker, but in his later life he went through bouts of excessive drinking and "his last years were characterized by unhappiness and depression" (Douglas, 2003, p. 274). For two mountaineers who had enjoyed and shared what was considered the ultimate achievement in the mountaineering domain, the contrast in their subsequent lives is stark.

Depending on different opportunities for fulfilling achievement aims, individuals may perceive that their only recourse to satisfying emotion regulation and agency needs is via more anti-social high-risk means such as criminal acts, reckless driving, drug use, etc. (cf. Klonsky, 2007). The potential convergence of the motivational processes that underlie such seemingly divergent activities certainly warrants research attention. Specifically, if antisocial risk-takers (e.g., criminals) were given opportunities to express their emotion regulation and agency needs in a high-risk constructive environment, it is possible that some of the risktaking benefits revealed in the present studies might help such individuals to engage in more constructive activities. In other words, the high-risk domain might be used as a learning ground for the self.

It is interesting to note that mountaineers' high expectations in the current studies share some of the characteristics of perfectionism, which, in its adaptive form, has been shown to be positively associated with achievement (Kobori, Yoshie, Kudo, \& Ohtsuki, 
2011; Rice \& Mirzadeh, 2000). Thus, if managed in an adaptive manner, a high expectancy of emotion regulation and agency may have a facilitative effect across multiple domains of a participant's life. Specifically, an individual with both adequate self-complexity (Larkin \& Griffiths, 2004) and self-efficacy (Bandura, 2006) should demonstrate positive striving in multiple compensatory activities across numerous domains (cf. Carver \& Scheier, 1998). The extent to which high-risk participants' high expectancies reflect an adaptive form of perfectionism is an interesting avenue for future research.

Conversely, the potential downward achievement spiral that might follow an inability to transfer the agency and emotion regulation benefits gleaned from the high-risk activity back into everyday life likely would lead to an impoverished life outside of the high-risk domain. Research that sheds light on the factors that moderate the ability of high-risk activity participants to translate their high achievement in the high-risk domain to other life domains certainly appears worthwhile. Equally, the extent to which one can benefit from engagement with high-risk activities as a way of elevating achievement standards appears worthy of research attention.

Beyond Risk: Implications for Personality Science. The SEAS was developed because there was no measure in the literature that specifically measures sensation seeking, emotion regulation or agency as motives for behavior. Although we were specifically interested in high-risk behavior, the measure can clearly be used for all behavior for which any of these three factors are thought to be at the core of the underlying motive. Furthermore, the implications of the present research extend considerably beyond risk-taking research, especially as this research answers a longstanding call for studies that move beyond the examination of college samples to examine participants' real-life behavior (Baumeister, Vohs, \& Funder, 2010; Carlson, 1971; Furr, 2009). Specifically, in contrast to most studies of personality where the researcher determines the setting and the associated behavior, the 
present paradigm places participants' personality at the centre of their spontaneously chosen behaviors and thus provides the possibility for an intricate understanding of the link between individual differences and behavior. In other words, in developing conceptual frameworks that drill down into the detail of what is specifically involved in engaging in behavior (i.e., the people and what they "do"), we stand to pave more completely the complex path between personality (in all its intricacy) and people's spontaneous behaviors (in all their intricacy; Sherman, Nave, \& Funder, 2010). The present in-depth investigation of specific individual motives and behaviors has allowed us to understand that the motives for seemingly similar behaviors can in fact be quite different from the theoretical framework with which personality researchers may have become comfortably accustomed. In the specific context of the present data, it is clear that people who spontaneously and actively engage with risk are not simply "sensation seekers." It is likely that other behaviors in personality research that have received a similarly glossed-over classification (e.g., pro-social behaviors; Gomà-iFreixanet, 2001) would also benefit from a finer grained analysis of the specific perceived benefits that individuals glean from the specific behaviors in which they engage, or indeed the specific threats that they perceive from not engaging in such behaviors. If we are to move beyond simplistic conceptualizations of complex behavior, and the contribution of individual differences therein, then personality researchers clearly need to embrace this complex challenge.

Methodological and Measurement Implications. These results have important implications for the continued study of motives for participation in high-risk activities. First, researchers should question the appropriateness of making inferences regarding the motives for participation in high-risk activities when the sample is drawn from a diverse range of high-risk activities and subsequently treated as a homogeneous sensation seeking group. Indeed, based on the present results, such methods may be a source of confound for much of 
the extant literature.

Second, the present research offers a methodologically valid avenue for investigating the motives for different activities. To date, the SSS-V (Zuckerman, 1979) has frequently been used for this purpose with high-risk activities. However, the SSS-V was neither designed for, nor capable of, measuring motives for different activities; it is simply a measure of the desire or propensity to engage in high-sensation activities and clearly has no place for the study of motives for such activities, especially when participants already engage in such activities. The lack of a suitable measure of sensation seeking motives has also been a limitation for previous research into specific high-risk samples. For example, with a view to understanding the specific anxiety regulation mechanisms in high-risk sport, researchers recently attempted to control for sensation seeking (e.g., Woodman, Cazenave, \& Le Scanff, 2008; Woodman, Huggins, Le Scanff and Cazenave, 2009). These studies demonstrated that, after controlling for scores on the SSS-V, skydiving served a specific anxiety regulation function for alexithymic individuals only. The question remains: do skydivers enjoy such anxiety regulation once sensation as a motive for participation (i.e., using the SEAS) is controlled? The present data suggest that the skydivers' emotion regulation reported in Woodman et al. (2009) was likely a reflection of a more salient underlying need for sensation. Thus, researchers would do well to distinguish between sensation seeking motives - in which case the SEAS would be appropriate - or attempts to study the propensity or desire to participate in so-called sensation seeking activities - in which case the SSS-V would be appropriate.

Limitations and Directions for Future Research. One limitation of the present studies is the retrospective data collection method utilized. That is, participant responses may have fluctuated as a function of the time elapsed since their previous participation in their chosen activity (cf. Yin, 2003) and this was not standardized across participants in the present 
design. Despite this limitation, we preferred retrospective data collection since this method tends to evaluate the individual's overall perception of the activity and thus has greater potential for examining the motives for repeated engagement in an activity (Stuart \& Hull, 1992). Since implementation of the SEAS is not limited to methodologies employing retrospective data collection, one solution to this limitation - and an interesting direction for future research - would be to employ the SEAS inventories in a prospective repeated measures design. Such a design would enable examination of the duration of the agentic emotion regulation transfer benefit and the satisfaction of sensation need gleaned as a result of participation. Furthermore, the factors that determine and maximize the magnitude of these benefits - for example the duration, intensity, and danger of the activity - could be addressed via such designs (cf. Norris \& Weinman, 1996). Of course, such questions are not limited to the investigation of high-risk activities and the between participations SEAS could be used for research on the motives for other activities for which there are thought to be sensation seeking, agency, or emotion regulation functions.

The present internet based data collection was limited by the strict safeguards that we established to prevent multiple responses from the same individual. We utilized "cookies" and "IP tracking" to ensure that participants were not duplicating responses. Such a solution to this potential problem is not without its own shortcomings, as potential participants may have inadvertently been excluded from the study when trying to complete the inventory from shared facilities. Despite this safeguard, one remaining statistical threat was the potential for participants to provide false information pertaining to their participation in high-risk activities and ability levels therein. Of course this potential problem is not limited to the use of equestionnaires, and beyond demanding proof of claimed participation and ability there is clearly no failsafe solution. Furthermore, that the hypothesized effects received consistent support across studies considerably mitigates this limitation. 
Conclusion. The findings in this paper provide consistent evidence that risk-takers are not, and should not be considered as, a homogenous group motivated by sensation seeking rewards. Some risk-takers - as exemplified by skydivers - are indeed motivated by the sensations of the activity. Other risk-takers - as exemplified by mountaineers - are motivated by the heightened emotion regulation and agency functions provided by the high-risk domain. The high-risk domain has the potential to provide a compelling illustration of how to live to one's potential and for each person to climb his/her own personal Mount Everest:

If you cannot understand that there is something in man which responds to the challenge of this mountain and goes out to meet it, that the struggle is the struggle of life itself upward and forever upward, then you won't see why we go (Mallory, 1924). 


\section{References}

Arnett, J. (1994). Sensation seeking: A new conceptualization and a new scale. Personality \& Individual Differences, 16, 289-296.

Bandura, A. (1997). Self efficacy: The exercise of control. New York: Freeman.

Bandura, A. (2001). Social cognitive theory: An agentic perspective. Annual Review of Psychology, 52, 1-26.

Bandura, A. (2006). Toward a psychology of human agency. Association for Psychological Science, 1, 164-180.

Barnett, S. M., \& Ceci, S. J. (2002). When and where do we apply what we learn? A taxonomy for far transfer. Psychological Bulletin, 128, 612-637.

Baumeister, R. F. Vohs, K. D., \& Funder, D. C. (2010). Psychology as the science of selfreports and finger movements: Whatever happened to actual behavior? In C.R.

Agnew, D. E. Carlston, W. G. Graziano, \& J. R. Kelly (Eds.), Then a miracle occurs: Focusing on behavior in social psychological theory and research (pp. 12-27). New York: Oxford University Press.

Bentler, P. M. (1990). Comparative fit indexes in structural models. Psychological Bulletin, 107, 238-246.

Breivik, G., Roth, W. T., \& Jørgensen, P. E. (1998). Personality, psychological states and heart rate in novice and expert parachutists. Personality \& Individual Differences, 25 , 365-380.

Campos, J. J., Frankel, C. B., \& Camras, L. (2004). On the nature of emotion regulation. Child Development, 75, 377-394. 
Carlson, R. (1971). Where is the person in personality research? Psychological Bulletin, 75, 203-219.

Carver, C. S., \& Scheier, M. F. (1998). On the self-regulation of behavior. New York: Cambridge University Press.

Castanier, C., Le Scanff, C., \& Woodman, T. (2010). Mountaineering as affect regulation: The moderating role of self-regulation strategies. Anxiety, Stress, and Coping, 24, 7589.

Cazenave, N., Le Scanff, C., \& Woodman, T. (2007). The personality and psychological profiles of women engaged in risk-taking sports. Anxiety, Stress, and Coping, 20, 421435.

Celsi, R. L., Rose, R. L., \& Leigh, T. W. (1993). An exploration of high-risk leisure consumption through skydiving. Journal of Consumer Research, 20, 1-23.

Chorpita, B. F., \& Barlow, D. H. (1998). The development of anxiety: The role of control in the early environment. Psychological Bulletin, 124, 3-21.

Cisler, J. M., Olatunji, B. O., Feldner, M. T., \& Forsyth, J. P. (2010). Emotion regulation and the anxiety disorders: An integrative review. Journal of Psychopathology \& Behavioral Assessment, 32, 68-82.

deCharms, R. (1968). Personal causation: The internal affective determinants of behavior. New York: Academic Press.

Deci, E. L., \& Ryan, R. M. (2002). Handbook of self-determination research. Rochester, NY: University of Rochester Press.

Diener, E., Larsen, R. J. \& Emmons, R. A. (1984). Person $\times$ Situation interactions: Choice of situations and congruence response models. Journal of Personality \& Social 
Psychology, 47, 580-592.

Douglas, E. (2003). Tenzing: Hero of Everest. Washington, D.C.: National Geographic.

Egan, S., \& Stelmack, R. M. (2003). A personality profile of Mount Everest climbers. Personality and Individual Differences, 34, 1491-1494.

Eskine, K. J., Kacinik, N. A., \& Prinz, J. J. (2012). Stirring images: Fear, not happiness or arousal, makes art more sublime. Emotion, doi: 10.1037/a0027200

Ewert, A. W. (1994). Playing the edge: Motivation and risk taking in a high-altitude wilderness like environment. Environment and Behavior, 26, 3-24.

Fenichel, O. (1939). The counterphobic attitude. International Journal of Psychoanalysis, 20, $263-274$.

Frederick, C. M., \& Ryan, R. M. (1995). Self-determination in sport: A review using cognitive evaluation theory. International Journal of Sport Psychology, 26, 5-23.

Furr, R. M. (2009). Personality psychology as a truly behavioral science. European Journal of Personality, 23, 369-401.

Gomà-i-Freixanet, M. (2001). Prosocial and antisocial aspects of personality in women: A replication study. Personality and Individual Differences, 30, 1401-1411.

Gosling, S. D., Rentfrow, P. J., \& Swann Jr. W. B. (2003). A very brief measure of the BigFive. Journal of Research in Personality, 37, 504-528.

Gross, J. J. (1998). The emerging field of emotion regulation: An integrative review. Review of General Psychology, 2, 271-299.

Gross, J. J. (2002). Emotion regulation: affective, cognitive, and social consequences. Psychophysiology, 39, 281-291. 
Gross, J. J., \& Thompson, R. A. (2007). Emotion regulation: Conceptual foundations. In J. J. Gross (Ed.), Handbook of emotion regulation (pp. 3-24). New York, NY: Guilford Press.

Gyurak, A., Gross, J. J., \& Etkin, A. (2011). Explicit and implicit emotion regulation: A dualprocess framework. Cognition \& Emotion, 25, 400-412.

Hattie, J., Marsh, H.W., Neil, J.T., \& Richards, G.E. (1997). Adventure education and Outward Bound: Out-of class experiences that make a lasting differences. Review of Educational Research, 67, 43 - 87.

Hunt, P., \& Daines, B. (2004). Defense processes enacted through mountaineering and their impact on climbers. British Journal of Psychotherapy, 20, 441-452.

JFK Library. (1962, September 12). 1962-09-12 Rice University [Video file]. Retrieved from http://www.jfklibrary.org/Asset-Viewer/MkATdOcdU06X5uNHbmqm1Q.aspx

Johnston, A. (2008). An extraordinary life: Sir Edmund Hillary. New York: Penguin group. Joinson, A. (1999). Social desirability, anonymity, and internet-based questionnaires. Behavior Research Methods, Instruments, and Computers, 31, 433-438.

Jöreskog, K. G. (1993). Testing structural equation models. In K. A. Bollen, \& J. S. Long (Eds.), Testing structural equation models (pp. 294-316). Newbury Park, CA: Sage.

Kirkpatrick, A. (2011). Cold Wars: climbing the fine line between risk and reality. Sheffield, UK: Vertebrae Graphics.

Klonsky, D. E. (2007). The functions of deliberate self-injury: A review of the evidence. Clinical Psychology Review, 27, 226-239.

Kobori, O., Yoshie, M., Kudo, K., \& Ohtsuki, T. (2011). Traits and cognitions of perfectionism and their relation with coping style, effort, achievement, and 
performance anxiety in Japanese musicians. Journal of Anxiety Disorders, 25, 674679.

Lansing, A. (1959). Endurance: Shackleton's incredible voyage. New York: Carroll \& Graf. Larkin, M., \& Griffiths, M. D. (2004). Dangerous sports and recreational drug-use: Rationalizing and contextualizing risk. Journal of Community \& Applied Social Psychology, 14, 215-232.

Leon, G. R., McNally, C., \& Ben-Porath, Y. S. (1989). Personality characteristics, mood, and coping patterns in a successful North Pole expedition team. Journal of Research in Personality, 23, 162-179.

Lester, J. (1983). Wrestling with the self on Mount Everest. Journal of Humanistic Psychology, 23, 31-41.

Lester, J. (2004). Spirit, identity, and self in mountaineering. Journal of Humanistic Psychology, 44, 86-100.

Little, T. D., Snyder, C. R., \& Wehmeyer, M. (2006). The agentic self: On the nature and origins of personal agency across the life span. In D. K. Mroczek, \& T. D. Little (Eds.), Handbook of Personality Development (pp. 61-80) Mahwah, NJ: LEA.

Llewellyn, D. J., \& Sanchez, X. (2008). Individual differences and risk taking in rock climbing. Psychology of Sport and Exercise, 9, 413-426.

Loewenstein, G. (2007). Because it is there: The challenge of mountaineering...For Utility Theory. In G. Loewenstein (Ed.), Exotic preferences: behavioral economics and human motivation (pp. 5-32).

Lupton, D., \& Tulloch, J. (2003). Risk and everyday life. London: Sage.

Lyng, S. (2005). Edgework: The sociology of risk taking. London: Routledge. 
Mallory, G. (1924/1999). Men and mountains: The gambler (Unpublished essay). In C.

Anker \& D. Roberts (Eds). Lost Explorer: Finding Mallory on Everest. London, England: Simon \& Schuster.

Mangunkusumo, R. T., Moorman, P. W., van den Berg-de Ruiter, A. E., Van Der Lei, J., De Koning, H. J., \& Raat, H. (2005). Internet-administered adolescent health questionnaires compared with a paper version in a randomized study. Journal of Adolescent Health, 36, 70.

Massumi, B. (1993). Introduction to fear. In B. Massumi (Ed.), The politics of everyday fear (pp. 3-38). Minneapolis: University of Minnesota Press.

Norris, R. M., \& Weinman, J. A. (1996). Psychological change during a long sail training voyage. Personality and Individual Differences, 21, 189-194.

Pain, M. T. G., \& Pain, M. A. (2005). Risk taking in sport. Lancet, 366, 33-34.

Paulhus, D. L. (1994). Balanced Inventory of Desirable Responding: Reference manual for BIDR Version 6. Unpublished manuscript, University of British Columbia, Vancouver, Canada.

Pearlin, L. I., \& Schooler, C. (1978). The structure of coping. Journal of Health and Social Behavior, 19, 2-21.

Qualtrics (2009). Qualtrics survey research suite (Version 11,834) [Computer software]. Provo, UT: Qualtrics Labs, Inc.

Rice, K. G., \& Mirzadeh, S. A. (2000). Perfectionism, attachment, and adjustment. Journal of Counselling Psychology, 47, 238-250.

Roberts, D. (1986). Moments of Doubt, and other mountaineering writings. Leicester, UK: Cordee. 
Sadock, B. J., \& Sadock, V. A. (2007). Kaplan \& Sadock's synopsis of psychiatry: Behavioral Sciences/Clinical Psychiatry (10th ed.). Philadelphia, PA: Lippincott Williams \& Wilkins.

Satorra, A., \& Bentler, P. M. (2001). A scaled difference chi-square test statistic for moment structure analysis. Psychometrika, 66, 507-514.

Sherman, R. A., Nave, C. S., \& Funder, D. C. (2010). Situational similarity and personality predict behavior. Journal of Personality \& Social Psychology, 99, 330-343.

Singley, K., \& Anderson, J. R. (1989). The transfer of cognitive skill. Cambridge, MA: Harvard University Press.

Slanger, E., \& Rudestam, K. E. (1997). Motivation and disinhibition in high risk sports: Sensation seeking and self-efficacy. Journal of Research in Personality, 31, 355-374. Sloman, A. (1987). Motives, mechanisms, and emotions. Cognition and Emotion, 7, 217-233.

Smith, C. W. (2005). Financial edgework: Trading in market currents. In S. Lyng, (Ed.), Edgework: The sociology of risk taking (pp. 187-202), London: Routledge.

Steiger, J. H., \& Lind, J. C. (1980). Statistically-based tests for the number of factors. Paper presented at the Annual Spring Meeting of the Psychometric Society, Iowa City, IA.

Stuart, W., \& Hull, R. B. (1992). Satisfaction of what? Post hoc versus real-time construct validity. Leisure Sciences, 14, 195-205.

Taylor, R. L., \& Hamilton, J. C. (1997). Preliminary evidence for the role of self-regulatory processes in sensation seeking. Anxiety, Stress, and Coping, 10, 351-375.

Tett, R. P., Fox, K. E., \& Wang, A. (2005). Development and validation of a self-report measure of emotional intelligence as a multidimensional trait domain. Personality \& Social Psychology Bulletin, 31, 859-888. 
Thompson, R. A. (1994). Emotion regulation: A theme in search of a definition. In N. A. Fox (Ed.), The development of emotion regulation: Biological and behavioral considerations (pp. 25-52). Chicago: University of Chicago Press.

Tucker, L. R., \& Lewis, C. (1973). A reliability coefficient for maximum likelihood factor analysis. Psychometrika, 38, 169-180.

Wicklund, R. A. (1975). Objective self-awareness. In L. Berkowitz (Ed.), Advances in experimental social psychology (Vol. 8, pp. 233-275). New York: Academic Press.

Woodman, T., Cazenave, N., \& Le Scanff, C. (2008). Skydiving as emotion regulation: The rise and fall of anxiety is moderated by alexithymia. Journal of Sport \& Exercise Psychology, 30, 424-433.

Woodman, T., Huggins, M., Le Scanff, C., \& Cazenave, N. (2009). Alexithymia determines the anxiety experienced in skydiving. Journal of Affective Disorders, 116, 134-138.

Woodman, T., Hardy, L., Barlow, M., \& Le Scanff, C. (2010). Motives for prolonged engagement high-risk sports: An agentic emotion regulation perspective. Psychology of Sport and Exercise, 11, 345-352.

Yin, R. K. (2003). Case study research: design and methods. London: Sage.

Zuckerman, M. (1979). Sensation seeking: Beyond the optimal level of arousal. Hillsdale, NJ: Erlbaum.

Zuckerman, M. (1994). Behavioral expressions and biosocial bases of sensation seeking. New York: Cambridge University Press.

Zuckerman, M. (2007). Sensation seeking and risky behavior. Washington, DC: American Psychological Association. 
Zuckerman, M. (2008). Rose is a rose is a rose: Content and construct validity. Personality and Individual Differences, 45, 110-112. 
Table 1.

Item-Factor loadings and model fit indices for the Between Participations Sensation seeking,

Emotion regulation and Agency Scale (SEAS) in Study 1.

BETWEEN PARTICIPATIONS, when I have not participated for a significant period...

Sensation Seeking Sample $1 \quad$ Sample 2

I want to get an adrenaline rush

$.72 \quad .57$

I look forward to getting a physical thrill from participating

$.70 \quad .80$

I look forward to the "rush" I hope to experience during participation $\quad .84 \quad .76$

I want to get a physical buzz

$.83 \quad .91$

I look forward to the physical sensations I will experience during

participation

I feel the need to do something intensely stimulating $\quad .59 \quad .57$

Coefficient alpha

$.87 \quad .87$

\section{Emotion Regulation}

The emotional elements of my life are difficult to deal with

$\begin{array}{ll}.74 & .75\end{array}$

I am emotional (e.g. anxious, angry) without understanding why

I struggle to deal with stressful situations in my life

I can't work out which emotion I am experiencing

$.56 \quad .65$

I find that emotional situations in my life stress me out

$.71 \quad .76$

I feel worried about other aspects of my life, not related to the task

Agency

I am prevented from achieving my goals in life

$.64 \quad .67$

I feel like a passive observer of my life rather than a major "actor"

I feel like people or circumstances are trying to impose limits on me

$.67 \quad .63$

I feel like my life "belongs" to other people

I feel trapped

.76

of my life

Coefficient alpha

Three-factor Model Fit Indices

\begin{tabular}{lcc}
$S-B \chi^{2}(132)$ & 231.40 & 244.00 \\
CFI & .97 & .96 \\
NNFI & .96 & .96 \\
RMSEA & $.06(p=.20)$ & $.06(p=.11)$ \\
SRMR & .05 & .06 \\
\hline
\end{tabular}

Notes: For Sample 1, the wording for the item stem was simply: "Before participating..."

S-B = Satorra-Bentler; CFI = Comparative Fit Index; NNFI = Non-Normed Fit Index; RMSEA = Root

Mean Square Error of Approximation; SRMR = Standardized Root Mean Residual. 
Table 2.

Item-Factor loadings and model fit indices for the While Participating Sensation seeking,

Emotion regulation and Agency Scale (SEAS) in Study 1.

\begin{tabular}{lcc}
\hline WHILE PARTICIPATING... & & \\
\hline$\quad$ Sensation Seeking & Sample 1 & Sample 2 \\
I enjoy getting a physical thrill & .82 & .74 \\
I experience intense excitement & .67 & .64 \\
I like to get a physiological buzz & .85 & .75 \\
I enjoy the sensations I experience & .71 & .57 \\
I get a rush of chemicals around my body that feels great & .65 & .76 \\
I experience physical sensations which feel great & .86 & .77 \\
$\quad$ Coefficient alpha & .88 & .85 \\
\hline
\end{tabular}

\section{Emotion Regulation}

My emotions are sometimes very intense $\quad .55 \quad .59$

I have to deal with stressful situations $\quad .57 \quad .51$

I have to manage my fear $\quad .52 \quad .53$

I prove to myself that I can deal with stressful situations $\quad .61$

I have to deal with intense emotions $\quad \begin{array}{ll}.75 \\ \text { The }\end{array}$

The emotions I experience are more intense than in other areas of my $\quad .51 \quad 52$

life

Coefficient alpha

$.75 \quad .75$

$$
\text { Agency }
$$

If a difficult situation arises I feel able to deal with it

$.49 \quad .39$

I am free from the constraints imposed on me in the rest of my life $\quad .41 \quad .53$

$\begin{array}{lll}\text { I choose how far to push when I am scared } & .68 & .40\end{array}$

I am in charge $\quad .65 \quad .50$

My actions and decisions prevent undesired outcomes from $\quad .54 \quad .47$

happening

No-one can force me to do something I don't want to do

Coefficient alpha

$.70 \quad .64$

Three-factor Model Fit Indices

\begin{tabular}{lcc}
$S-B \chi^{2}(132)$ & 223.32 & 224.84 \\
CFI & .96 & .94 \\
NNFI & .96 & .94 \\
RMSEA & $.05(p=.31)$ & $.05(p=.38)$ \\
SRMR & .07 & .07 \\
\hline
\end{tabular}


Table 3.

Item-factor loadings and model fit indices for the After Participating Sensation seeking,

Emotion regulation and Agency Scale (SEAS) in Study 1.

\begin{tabular}{|c|c|c|}
\hline \multicolumn{3}{|l|}{ AFTER PARTICIPATING... } \\
\hline \multirow{2}{*}{\multicolumn{3}{|c|}{ Sensation Seeking }} \\
\hline & & \\
\hline I enjoy the feeling of adrenaline flowing around my body & .73 & .74 \\
\hline I feel like I have satisfied my immediate need for thrill & .69 & .57 \\
\hline I am often buzzing from the adrenaline & .84 & .84 \\
\hline $\begin{array}{l}\text { I remember how good the sensations felt during participation and want to } \\
\text { experience them again }\end{array}$ & .66 & .56 \\
\hline I enjoy the rush of chemicals still flowing round my body & .84 & .88 \\
\hline I look back and think how much I enjoyed the rush & .81 & 71 \\
\hline Coefficient alpha & .89 & .87 \\
\hline \multicolumn{3}{|l|}{ Agentic Emotion Regulation } \\
\hline Coefficient alpha & .95 & .92 \\
\hline \multicolumn{3}{|l|}{ (Agency) } \\
\hline I feel more able to deal with stressful situations in my life & .74 & .67 \\
\hline I feel I have demonstrated that I can deal with intense emotions & .70 & .67 \\
\hline I find intense emotions easier to deal with & .82 & .80 \\
\hline I find it easier to deal with stressful situations in my life & .80 & .75 \\
\hline I feel better for having experienced my emotions & .69 & .53 \\
\hline $\begin{array}{l}\text { I feel better able to deal with aspects of my life that would normally make } \\
\text { me feel emotional (e.g., anxious, angry) }\end{array}$ & .78 & .74 \\
\hline Coefficient alpha & .89 & .89 \\
\hline \multicolumn{3}{|l|}{ (Emotion regulation) } \\
\hline I have a calmness that carries over into other aspects of my life & .58 & .49 \\
\hline $\begin{array}{l}\text { I am more confident that I can affect those aspects of my life that are } \\
\text { important to me }\end{array}$ & .82 & .80 \\
\hline I am more confident about facing challenges in other aspects of my life & .81 & .79 \\
\hline I feel more influential in how events in my life unfold & .87 & .80 \\
\hline I feel better about my ability to bring about important outcomes in my life & .83 & .73 \\
\hline I feel more able to prevent difficulties occurring in other aspects of my life & .81 & .75 \\
\hline Coefficient alpha & .91 & .87 \\
\hline \multicolumn{3}{|l|}{ Three-factor Model Fit Indices } \\
\hline$S-B \chi^{2}(132)$ & 228.24 & 234.19 \\
\hline CFI & .98 & .97 \\
\hline NNFI & .97 & .96 \\
\hline RMSEA & $.06(p=22)$ & $.06(p=.18)$ \\
\hline SRMR & .06 & .07 \\
\hline \multicolumn{3}{|l|}{ Two-factor Model Fit Indices } \\
\hline$S-B \chi^{2}(132)$ & 233.75 & 234.84 \\
\hline CFI & .98 & .97 \\
\hline NNFI & .97 & .96 \\
\hline RMSEA & $.06(p=.12)$ & $.06(p=.18)$ \\
\hline SRMR & .06 & .07 \\
\hline
\end{tabular}


Table 4.

Differences between Mountaineers, Skydivers, and Low-risk controls for Sensation Seeking, Emotion Regulation, and Agency before, while, and after participating in Study 2.

\begin{tabular}{|c|c|c|c|c|}
\hline & $\begin{array}{l}\text { Mountaineers } \\
\quad(n=28)\end{array}$ & $\begin{array}{c}\text { Skydivers } \\
(n=35)\end{array}$ & $\begin{array}{c}\text { Low-risk control } \\
\quad(n=28)\end{array}$ & $\begin{array}{l}\text { Omnibus between-groups } \\
\text { difference }\end{array}$ \\
\hline Need for Sensation & $4.87(1.43)$ & $5.72(1.01)^{\mathrm{a}}$ & $4.59(1.26)$ & $F(2,88)=7.37, p<.001$ \\
\hline Diminished Agency & $2.30(1.21)$ & $2.32(1.15)$ & $1.98(0.90)$ & $F(2,88)=0.85, p=.43$ \\
\hline \multicolumn{5}{|l|}{ While participating } \\
\hline Experience of Sensation & $5.40(1.15)$ & $6.06(0.77)^{\mathrm{a}}$ & $4.88(1.14)$ & $F(2,88)=10.67, p<.001$ \\
\hline Experience of Agency & $5.29(1.09)^{\mathrm{b}}$ & $5.71(0.77)^{\mathrm{b}}$ & $4.53(0.98)$ & $F(2,87)=3.39, p<.05$ \\
\hline \multicolumn{5}{|l|}{ After participating } \\
\hline Satisfaction of Sensation Need & $5.06(1.12)$ & $5.90(1.08)^{\mathrm{a}}$ & $4.63(1.33)$ & $F(2,88)=9.70, p<.001$ \\
\hline Agentic Emotion Regulation & $4.57(1.34)^{\mathrm{a}}$ & $4.19(1.34)$ & $3.42(1.29)$ & $F(2,87)=5.06, p<.01$ \\
\hline
\end{tabular}

Note: ${ }^{\mathrm{a}}=$ significantly greater than the other two groups; ${ }^{\mathrm{b}}=$ significantly greater than the control group. 
Table 5.

Correlations between the Between Participations SEAS subscales and other established personality constructs in Study 3 ( $\mathrm{n}=112$ ).

\begin{tabular}{|c|c|c|c|c|c|c|c|c|c|c|c|c|c|}
\hline & 1. & 2. & 3. & 4. & 5. & 6. & 7. & 8. & 9. & 10. & 11. & 12. & 13. \\
\hline 1. SEAS Sensation seeking & .85 & & & & & & & & & & & & \\
\hline 2. SEAS Emotion Regulation & .14 & .82 & & & & & & & & & & & \\
\hline 3. SEAS Agency & .13 & $.77 * * *$ & .85 & & & & & & & & & & \\
\hline 4. Sensation seeking & $.25 * *$ & .13 & .02 & .79 & & & & & & & & & \\
\hline 5. Emotion regulation & -.05 & $-.44 * * *$ & $-.26 * *$ & .03 & .83 & & & & & & & & \\
\hline 6. Lack of Mastery & .05 & $.53 * * *$ & $.58 * * *$ & -.14 & $-.50 * * *$ & .82 & & & & & & & \\
\hline 7. Extraversion & $.21 *$ & -.09 & -.10 & $.23 *$ & .05 & -.18 & .58 & & & & & & \\
\hline 8. Conscientiousness & -.10 & $-.21 *$ & $-.22 *$ & -.02 & $.34 * * *$ & $-.27 * *$ & .04 & .41 & & & & & \\
\hline 9. Openness & .12 & -.04 & -.15 & $.22 *$ & .08 & $-.22 *$ & $.37 * * *$ & .12 & .37 & & & & \\
\hline 10. Emotional stability & -.08 & $-.44 * * *$ & $-.24 *$ & .05 & $.74 * * *$ & $-.45 * * *$ & .00 & $.23 *$ & .07 & .59 & & & \\
\hline 11. Agreeableness & .02 & -.11 & -.04 & -.05 & .11 & -.01 & -.04 & -.07 & -.09 & $.28 * *$ & .31 & & \\
\hline 12. Impression management & $-.26 * *$ & .02 & .14 & $-.38 * *$ & $.21 *$ & .13 & $-.31 * *$ & .17 & -.12 & .04 & -.03 & .76 & \\
\hline 13. Self-deception enhancement & -.04 & $-.33 * *$ & $-.29 * *$ & .04 & $.58 * *$ & $-.49 * *$ & .15 & $.38 * *$ & $.21 *$ & $.49 * *$ & .01 & .02 & .68 \\
\hline
\end{tabular}

Note: $* * * p<.001 ; * * p<.01 ; * p<.05$. SEAS Sensation seeking = Need for sensation; SEAS Emotion Regulation = Difficulty with Emotion Regulation; SEAS Agency = Diminished Agency; Sensation seeking = total score on Zuckerman's Sensation Seeking Scale; Emotion Regulation = the ability to regulate one's own emotions from Tett et al.'s (2005) Emotional Intelligence Scale; Agency = General perceived lack of mastery from Pearlin and Schooler's (1978) inventory;

Extraversion, Conscientiousness, Openness to new experience, Emotional stability, and Agreeableness from Gosling et al.'s (2003) Ten-Item Personality Inventory;

Impression management and self-deception enhancement from Paulhus' (1994) Balanced Inventory of Desirable Responding. Coefficient alphas are on the diagonal. 
Table 6.

Differences between Mountaineers, Skydivers, and Low-risk controls for the Sensation Seeking, Emotion Regulation, and Agency between participations and previously established measures of Sensation Seeking, Emotion Regulation, Agency, Personality, and Social Desirability in Study 3.

\begin{tabular}{|c|c|c|c|c|}
\hline & $\begin{array}{c}\text { Mountaineers } \\
(n=39)\end{array}$ & $\begin{array}{l}\text { Skydivers } \\
(n=41)\end{array}$ & $\begin{array}{c}\text { Low-risk control } \\
(n=32)\end{array}$ & $\begin{array}{l}\text { Omnibus between-groups } \\
\text { difference }\end{array}$ \\
\hline \multicolumn{5}{|l|}{ SEAS Between participations } \\
\hline Need for Sensation & $5.27(1.15)$ & $6.10(0.84)^{\mathrm{c}}$ & $5.69(0.85)$ & $F(2,109)=7.39, p<.001$ \\
\hline Difficulty with Emotion Regulation & $3.12(1.25)$ & $2.82(1.24)$ & $2.95(1.29)$ & $F(2,109)=0.58, p>.50$ \\
\hline Diminished Agency & $3.02(1.38)$ & $2.59(1.31)$ & $2.79(1.42)$ & $F(2,109)=0.98, p=.38$ \\
\hline Sensation Seeking & $25.67(5.09)^{\mathrm{b}}$ & $26.15(4.91)^{\mathrm{b}}$ & $21.78(6.06)$ & $F(2,109)=6.97, p<.01$ \\
\hline Lack of Mastery & $1.78(0.67)$ & $1.62(0.61)$ & $1.91(0.59)$ & $F(2,109)=1.87, p=.16$ \\
\hline Ability to Regulate One's Emotions & $4.54(0.56)^{\mathrm{b}}$ & $4.51(0.77)^{\mathrm{b}}$ & $3.91(0.82)$ & $F(2,109)=8.46, p<.001$ \\
\hline \multicolumn{5}{|l|}{ Social Desirability } \\
\hline Impression management & $3.72(.80)$ & $3.48(.78)$ & $3.71(.70)$ & $F(2,109)=1.29, p=.28$ \\
\hline Self-deception enhancement & $4.41(.57)$ & $4.56(.54)^{\mathrm{b}}$ & $4.15(.62)$ & $F(2,109)=4.70, p<.05$ \\
\hline \multicolumn{5}{|l|}{ Personality } \\
\hline Extraversion & $4.42(1.11)$ & $4.37(1.62)$ & $4.67(1.31)$ & $F(2,109)=0.49, p>.50$ \\
\hline Emotional Stability & $5.79(0.77)^{\mathrm{b}}$ & $5.80(1.20)^{\mathrm{b}}$ & $5.05(1.07)$ & $F(2,109)=6.12, p<.05$ \\
\hline Openness & $5.67(1.16)$ & $5.76(1.02)$ & $5.69(0.98)$ & $F(2,109)=0.08, p>.50$ \\
\hline Conscientiousness & $5.64(1.04)^{b}$ & $5.28(1.14)$ & $4.91(1.13)$ & $F(2,109)=3.91, p<.05$ \\
\hline Agreeableness & $4.82(1.11)$ & $4.82(1.24)$ & $4.73(1.03)$ & $F(2,109)=0.06, p>.50$ \\
\hline
\end{tabular}

Note: ${ }^{\mathrm{a}}=$ significantly greater than the other two groups; ${ }^{\mathrm{b}}=$ significantly greater than the control group; ${ }^{\mathrm{c}}=$ significantly greater than mountaineers. Sensation seeking $=$ total score on Zuckerman's (1979) Sensation Seeking Scale; Emotion Regulation = the ability to regulate one's own emotions from Tett et al.'s (2005) Emotional Intelligence Scale; Agency = General perceived lack of mastery from Pearlin and Schooler's (1978) inventory; Extraversion, Conscientiousness, Openness to new experience, Emotional stability, and Agreeableness from Gosling et al.'s (2003) Ten-Item Personality Inventory; Impression management and self-deception enhancement from Paulhus' (1994) Balanced Inventory of Desirable Responding. 
Table 7.

Multiple logistic regression analysis for predicting high-risk activity as a function of Zuckerman's (1979) SSS-V subscales and the SEAS Need for Sensation.

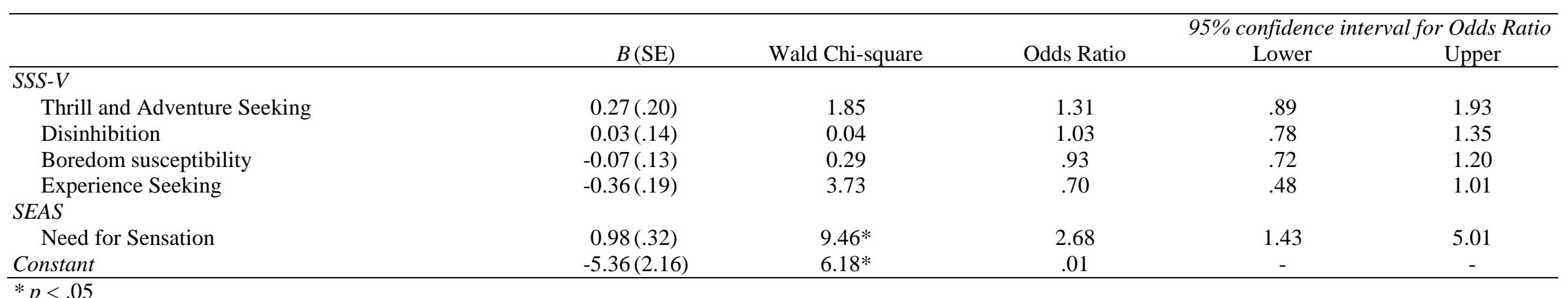


Table 8.

Differences between Mountaineers, Skydivers, and Low-risk controls for the Sensation Seeking, Emotion Regulation, and Agency in SEAS

Between, While, and After participating in Study 4.

\begin{tabular}{|c|c|c|c|c|}
\hline & $\begin{array}{c}\text { Mountaineers } \\
\quad(n=46)\end{array}$ & $\begin{array}{l}\text { Skydivers } \\
(n=100)\end{array}$ & $\begin{array}{c}\text { Low-risk control } \\
\quad(n=47) \\
\end{array}$ & $\begin{array}{l}\text { Omnibus between-groups } \\
\text { difference }\end{array}$ \\
\hline \multicolumn{5}{|l|}{ Between participations } \\
\hline Need for Sensation & $5.07(1.25)$ & $5.64(1.30)^{\mathrm{a}}$ & $5.05(1.26)$ & $F(2,190)=5.01, p<.01$ \\
\hline \multicolumn{5}{|c|}{ Multivariate Emotion Regulation analysis } \\
\hline Difficulty with Emotion Regulation & $3.61(1.45)^{\mathrm{d}}$ & $3.06(1.37)$ & $3.43(1.58)$ & $F(4,378)=2.69, p<.05$ \\
\hline Emotion Regulation Expectancy & $3.84(1.73)^{\mathrm{d}}$ & $2.90(1.58)$ & $3.28(1.74)$ & Wilks' $\Lambda=.95$ \\
\hline \multicolumn{5}{|l|}{ Multivariate Agency analysis } \\
\hline Diminished Agency & $3.12(1.32)^{\mathrm{d}}$ & $2.81(1.29)$ & $2.79(1.46)$ & $F(4,378)=2.67, p<.05$ \\
\hline Agency Expectancy & $3.89(1.81)^{\mathrm{d}}$ & $2.96(1.58)$ & $2.94(1.70)$ & Wilks' $\Lambda=.95$ \\
\hline \multicolumn{5}{|l|}{ While participating } \\
\hline Experience of Sensation & $5.18(0.88)$ & $5.80(0.87)^{\mathrm{a}}$ & $5.23(0.92)$ & $F(2,190)=10.82, p<.001$ \\
\hline Experience of Emotion Regulation & $5.71(0.79)^{\mathrm{a}}$ & $5.00(0.97)^{b}$ & $4.22(1.11)$ & $F(2,189)=34.80, p<.001$ \\
\hline Experience of Agency & $5.46(0.74)^{b}$ & $5.64(0.73)^{b}$ & $4.81(0.96)$ & $F(2,189)=13.21, p<.001$ \\
\hline \multicolumn{5}{|l|}{ After participating } \\
\hline Satisfaction of Sensation Need & $4.71(1.22)$ & $5.48(1.02)^{\mathrm{a}}$ & $4.99(1.09)$ & $F(2,190)=8.86, p<.001$ \\
\hline Agentic Emotion Regulation & $4.92(1.25)^{\mathrm{a}}$ & $4.59(1.10)$ & $4.29(1.40)$ & $F(2,189)=6.58, p<.005$ \\
\hline
\end{tabular}

Note: ${ }^{\mathrm{a}}=$ significantly greater than the other two groups; ${ }^{\mathrm{b}}=$ significantly greater than the control group. ${ }^{\mathrm{d}}=$ multivariate discriminant from the other two groups following examination of the discriminant function at group centroids. 